\title{
Formal Syntheses of Dictyodendrins B, C, and E by a Multi-substi- tuted Indole Synthesis
}

\author{
Akira Kabuki and Junichiro Yamaguchi* \\ Department of Applied Chemistry, Waseda University, 513 Wasedatsurumakicho, Shinjuku, Tokyo 162-0041, Japan \\ Supporting Information Placeholder
}

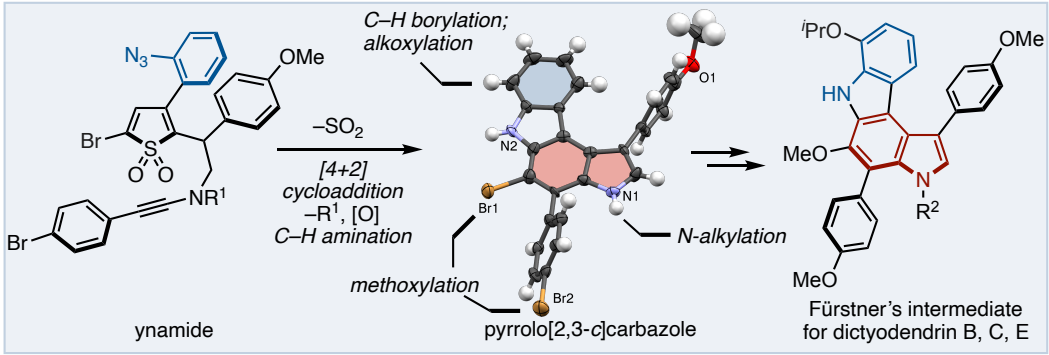

\begin{abstract}
The dictyodendrins are a family of marine alkaloids, which possess a highly substituted pyrrolo[2,3-c]carbazole core. This core structure can be regarded as a multi-substituted indole and aniline moiety. To achieve a concise synthesis of dictyodendrins, we planned to capitalize on our previously developed multi-substituted indole synthesis. By using this method along with two C-H functionalizations, formal syntheses of dictyodendrin B, C, and E were achieved.
\end{abstract}

Dictyodendrins A-J are alkaloids from marine sponges (Figure 1A). Of these compounds, dictyodendrins A-E were isolated from the Japanese sponge Dictyodendrilla verongiformis, and structurally assigned by Fusetani and Matsunaga in 2003. ${ }^{[1 \mathrm{a}]}$ These are the first natural marine products to show telomerase inhibitory activity, and therefore could potentially be lead compounds for anticancer drugs. $^{[2]}$ Dictyodendrins F-J were isolated from an Australian sponge of the genus Ianthella by Capon and coworkers in 2012..$^{[1 \mathrm{~b}]}$ These natural products have $\beta$-selectase ( $\beta$-site APP-cleaving enzyme: BACE) inhibitory activity, which is expected to be applied to the research of Alzheimer's disease. ${ }^{[3]}$ As a structural feature, all analogues except dictyodendrin J possess a highly substituted pyrrolo[2,3-c] carbazole core.

Dictyodendrins have attracted attention as synthetic targets due to their important biological activities and unique structures, and to date, nine research groups have reported total syntheses including our group. ${ }^{[4]}$ Pyrrolo[2,3-c] carbazole, the main skeleton of dictyodendrins, is a ring-fused structure of pyrrole and carbazole, but it can also be regarded as a structure in which an aniline is attached to the $\mathrm{C} 4$ and $\mathrm{C} 5$ positions of an indole. There have been three reports on the synthesis of dictyodendrins using the construction of the main skeleton by connecting the indole with the aniline moiety (Figure 1B). Tokuyama and co-workers reported the synthesis of dictyodendrins by benzyne-mediated cyclization and cross-coupling/C-H amination of multi-substituted indoles with aryl azides. ${ }^{[4,, f]} \mathrm{Jia}$ and coworkers constructed the main skeleton by Buchwald-Hartwig amination of the multi-substituted indole obtained from the Larock indole synthesis with an aniline moiety, followed by intramolecular $\mathrm{C}-\mathrm{H}$ arylation. ${ }^{[4 \mathrm{~h}]}$ Gaunt and coworkers reported an elegant synthesis using $\mathrm{C}-\mathrm{H}$ functionalization leading to multi-substituted indoles, and then conducted a Suzuki-Miyaura coupling with aryl azides (aniline moiety), followed by intramolecular $\mathrm{C}-\mathrm{H}$ amination to form the main skeleton. ${ }^{[4]}$ In all of these synthetic examples, the unique indole synthetic method was key. Hence, we proposed that an efficient synthesis of the dictyodendrin family could be achieved through the synthesis of a multi-substituted indole by a coupling/ring transformation strategy developed in our laboratory (Figure $1 C) .{ }^{[5]}$ In this method, an ynamide intermediate containing thiophene- $S, S$-dioxide was synthesized by a simple four-unit coupling reaction. Then, the ynamide was reacted with the thiophene- $S, S$-dioxide via an inverse-electron-demand [4+2] cycloaddition and oxidation/deprotection to give pentaarylindole (PAI). Subsequent two-fold arylation of PAI led to heptaarylindole (HAI), in which all $\mathrm{C}-\mathrm{H} / \mathrm{N}-\mathrm{H}$ bonds of the indole are substituted with aryl groups ${ }^{[6]} \mathrm{A}$ variety of multi-substituted indoles can be synthesized by simply changing the substituents at each site. Based on this multi-substituted indole synthesis, we set out to synthesize the dictyodendrin family (Figure 1D). As a forward synthetic plan, ynamide [4+2] cycloaddition would afford a multi-substituted indoline, followed by oxidation/C-H amination to a pyrrolo[2,3-c] carbazole. After several functionalizations including a $\mathrm{C}-\mathrm{H}$ functionalization to the pyrrolocarbazole, the compound would lead to a synthetic intermediate 


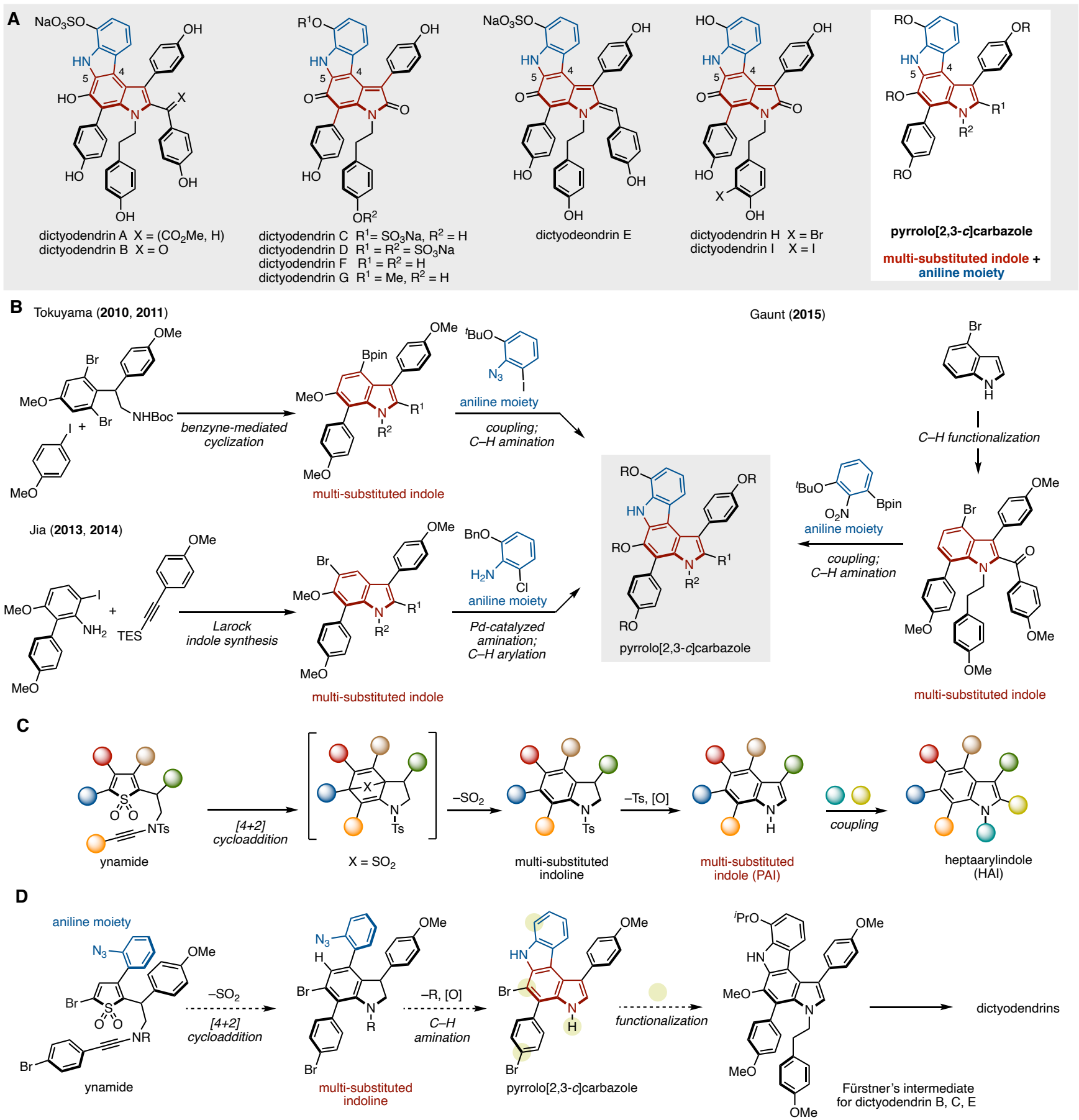

Figure 1. (A) Structures of dictyodendrin A-I. (B) Syntheses of dictyodendrins using the construction of the main skeleton by connecting an indole with an aniline moiety. (C) Our multi-substituted(arylated) indole synthesis. (D) Our synthetic strategy toward dictyodendrins B, C, and E.

of dictyodendrins B, C, and E that was generated by Fürstner and

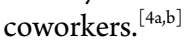

First, the synthesis of the key multi-substituted indoline was conducted (Scheme 1A). The synthesis was commenced with a SuzukiMiyaura coupling of 1-azido-2-bromobenzene (1) with 3-thiopheneboronic acid (2) in the presence of a palladium catalyst and base to afford 3-arylthiophene 3 in 94\% yield. Alcohol 5 was synthesized by epoxide opening of 2-(4-methoxyphenyl)oxirane (4) with 3-arylthiophenes under Lewis acid conditions. Although we extensively investigated this epoxide-opening reaction using various Lewis acids and conditions, TMSOTf gave the best results to give alcohol $\mathbf{5}$ in a low $23 \%$ yield, along with $48 \%$ recovered starting material 3 (see the supporting information for details). ${ }^{[7]}$ Alcohol $\mathbf{5}$ was subsequently converted to amide 6 by Mitsunobu reaction with NHBocNs and removal of the Boc group, followed by bromination at the C5-position of the thiophene to afford Ns-amide 6 in 57\% yield over 3 steps. In order to examine the $[4+2]$ cycloaddition with ynamides, the synthesis of two thiophene oxides 7 and 8 was carried out. Thiophene $S, S$-dioxide 7 can be readily prepared by oxidation with $m$ CPBA. $S$ Oxide 8 was also prepared using $m C P B A$ in the presence of an excess 
amount of $\mathrm{BF}_{3} \cdot \mathrm{OEt}_{2}$ to suppress over-oxidation. ${ }^{[6 \mathrm{a}]}$ Then, ynamide formation from 7 and 8 with alkynylating agents, followed by [4+2] cycloaddition, was investigated (Scheme 1B). After screening of several alkylation conditions (see the supporting information for details), when hypervalent iodine alkynylating agent 9 and $\mathrm{Cs}_{2} \mathrm{CO}_{3}$ were used, ${ }^{[8]}$ we successfully obtained desired indoline 10 in $42 \%$ yield from $S, S$-dioxide 7 and in $29 \%$ yield from $S$-oxide 8 . Since the yield of $\mathbf{1 0}$ from $S, S$-dioxide $\mathbf{7}$ was higher than that of $S$-oxide $\mathbf{8}$, we selected 7 as the more appropriate precursor. To make dictyodendrins, we also reacted 7 with a bromo-bearing alkynylating agent 11 and succeeded in producing the desired indoline 12 in $42 \%$ yield.

Scheme 1. (A) Preparation of $S$-Oxide and $S, S$-Dioxide. (B) Ynamide Formation and $[4+2]$ Cycloaddition $^{\mathrm{a}}$

A
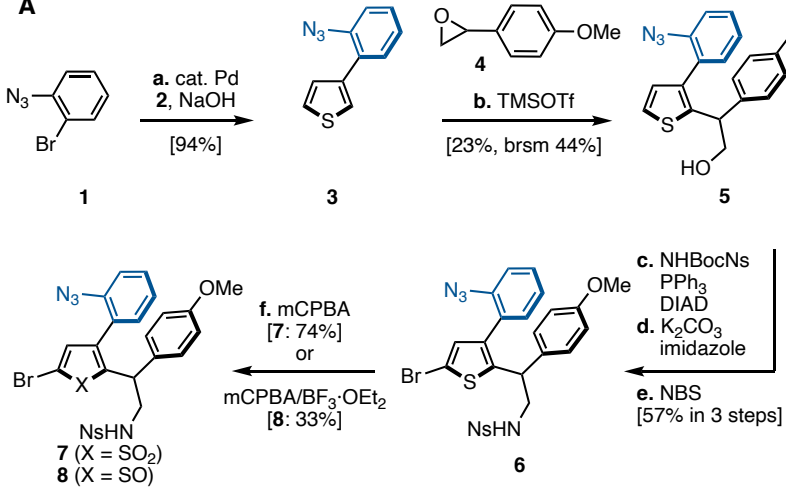

6
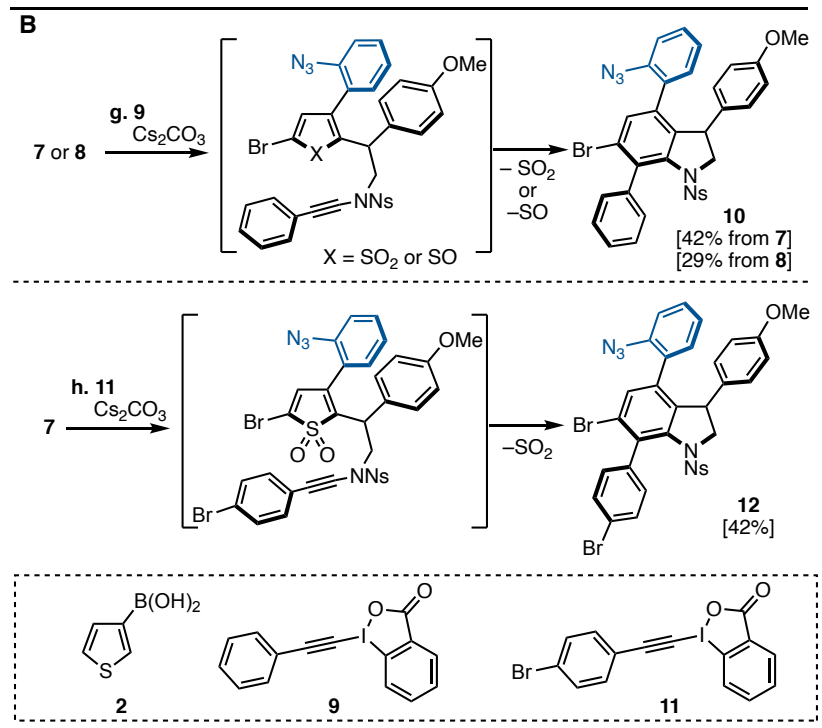

${ }^{a}$ Conditions. (a) 3-Thiopheneboronic acid (2: 1.5 equiv), $\mathrm{Pd}_{2}(\mathrm{dba})_{3} \cdot \mathrm{CHCl}_{3}(0.70 \mathrm{~mol} \%), \mathrm{P}\left({ }^{t} \mathrm{Bu}\right)_{3} \cdot \mathrm{HBPh}_{4}(1.4 \mathrm{~mol} \%), \mathrm{NaOH}$ aq (3.0 equiv), THF, $65^{\circ} \mathrm{C}, 4 \mathrm{~h}$ (94\%); (b) 4 (1.0 equiv), TMSOTf ( 2.0 equiv), $\mathrm{CH}_{2} \mathrm{Cl}_{2},-78{ }^{\circ} \mathrm{C}, 2 \mathrm{~h}(23 \%+48 \%$ recovered 3$)$; (c) NHBocNs (1.7 equiv), DIAD ( 1.7 equiv), THF, $0^{\circ} \mathrm{C}, 12 \mathrm{~h}$; (d) $\mathrm{K}_{2} \mathrm{CO}_{3}$ ( 5.0 equiv), imidazole ( 5.0 equiv), $\mathrm{MeCN}, 60^{\circ} \mathrm{C}, 12 \mathrm{~h}$; (e) NBS (1.0 equiv), THF RT, 9 h ( $57 \%$ in 3 steps); (f) for $7: m C P B A$ ( 2.5 equiv), 1,2-dichloroethane, $65{ }^{\circ} \mathrm{C}, 6 \mathrm{~h}(74 \%)$; for $8: \mathrm{BF}_{3} \cdot \mathrm{OEt}_{2}$ (10 equiv), $m \mathrm{CPBA}$ (1.0 equiv), $\mathrm{CH}_{2} \mathrm{Cl}_{2},-20{ }^{\circ} \mathrm{C}, 1 \mathrm{~h}(33 \%) ;(\mathrm{g}) \mathrm{Cs}_{2} \mathrm{CO}_{3}$ ( 1.5 equiv), 9 ( 1.5 equiv), 1,4-dioxane, $80^{\circ} \mathrm{C}, 12 \mathrm{~h}$ ( $42 \%$ from $7,29 \%$ from 8 ); (h) $\mathrm{Cs}_{2} \mathrm{CO}_{3}$ (2.8 equiv), 11 ( 1.5 equiv), 1,4-dioxane, $50^{\circ} \mathrm{C}, 12 \mathrm{~h}(42 \%)$.

Next, we attempted to access Fürstner's intermediate from the obtained indoline 12 (Scheme 2). From 12, pyrrolocarbazole 13 could be synthesized with intramolecular $\mathrm{C}-\mathrm{H}$ amination, ${ }^{[4 \mathrm{e}, \mathrm{f}, \mathrm{j}]}$ removal of the nosyl group, then oxidation of the indoline to the corresponding indole. First, the $\mathrm{C}-\mathrm{H}$ amination of $\mathbf{1 2}$ was investigated by heating at $160{ }^{\circ} \mathrm{C}$ in $o$-dichlorobenzene. The expected indoline was not obtained, but surprisingly, the desired pyrrolocarbazole 13 was directly obtained in $16 \%$ yield, indicating spontaneous denosylation and oxidation. Pyrrolocarbazole 13 was crystallized from toluene/hexane and its structure was confirmed by X-ray crystallographic analysis. Although the three reactions proceeded efficiently in a single step, several undetermined byproducts were formed, resulting in low yields. We hypothesized that the cause of the complexity of the reaction was due to the acid generated during the removal of the nosyl group. Therefore, $\mathrm{K}_{2} \mathrm{CO}_{3}$ was added to neutralize the acid, and the yield of 13 significantly improved to $64 \%$.

We then attempted a formal syntheses of dictyodendrins B, C, and $\mathrm{E}$ by elaborating the resulting pyrrolocarbazoles to known synthetic intermediates. From 13, an isopropoxy group needed to be introduced at the $\mathrm{C} 7$ position, an alkyl chain needed to be installed at the $\mathrm{N} 3$ position, and the $\mathrm{C}-\mathrm{Br}$ bond needed to be methoxylated to reach the synthetic intermediate of Fürstner and coworkers. First, for the isopropoxylation of the $\mathrm{C} 7$ position, we selected $\mathrm{C}-\mathrm{H}$ borylation. When pyrrolocarbazole $\mathbf{1 3}$ was subjected to iridium-catalyzed $\mathrm{C}-\mathrm{H}$ borylation conditions, ${ }^{[9]}$ only the compound with borylation at the $\mathrm{C} 2$ position, not the $\mathrm{C} 7$ position, was obtained in $62 \%$ yield when 1.4 equiv of $\mathrm{B}_{2} \mathrm{pin}_{2}$ was used. When the amount of $\mathrm{B}_{2}$ pin ${ }_{2}$ was increased to 2.6 equiv, compound 14 with borylated $\mathrm{C} 2$ and $\mathrm{C} 7$ positions was obtained in $66 \%$ yield as judged by ${ }^{1} \mathrm{H}$ NMR. It should be noted that $\mathbf{1 4}$ and other borylated products were unstable to purification by silica gel column chromatography, and these compounds could not be isolated. Although C7-selective borylation was not achieved, introducing a boryl group at the $\mathrm{C} 7$ position was successful. Then, we considered that if C7-selective isopropoxylation or C2-selective protodeborylation of $\mathbf{1 4}$ were possible, we would be able to generate the desired product $\mathbf{1 5}$. To this end, a chemoselective isopropoxylation at the $\mathrm{C} 7$ position was conducted by using $\mathrm{Cu}(\mathrm{OAc})_{2}$ as an oxidant and DMAP/4 $\mathrm{MS}$ as additives onto 14 in a mixture of $\mathrm{CH}_{2} \mathrm{Cl}_{2}$ and $\mathrm{PrOH}^{[9]}$ As a result, not only the isopropoxylation of the $\mathrm{C} 7$ position, but also the protodeborylation of the $\mathrm{C} 2$ position proceeded under these conditions, and desired 15 was successfully obtained in a single step ( $33 \%$ yield, $22 \%$ in two steps from 13 ), along with recovered 13 in $21 \%$ yield. We believe that the regioselective protodeborylation is possible because the electron-rich $\mathrm{C} 2$ position is easily protonated. ${ }^{[10]}$ Next, for the alkylation of $\mathbf{1 5}$ at the $\mathrm{N} 1$ position, treatment of $\mathbf{1 5}$ with alkyl tosylate and potassium hydroxide gave the desired N2-alkylated product 17, but the yield was only $5 \%$. Contrary to our expectations, the $N$-alkylation product was preferentially obtained. After extensive investigation, the desired product 17 was obtained with complete $\mathrm{N} 1$ selectivity and moderate yield when the leaving group was changed to bromide (16), the base was modified to $\mathrm{NaOH}$, and 18-crown- 6 was employed as an additive. ${ }^{[41]}$ Finally, methoxylation of the two bromo atoms of 17 with copper iodide and sodium methoxide led to the synthetic intermediate of Fürstner and coworkers, thus completing the formal synthesis of dictyodendrins $\mathrm{B}, \mathrm{C}$, and $\mathrm{E}$.

In summary, we have accomplished the formal syntheses of dictyodendrins by a multi-substituted indole synthesis. We constructed a highly substituted pyrrolocarbazole skeleton by alkynylation and intramolecular $\mathrm{C}-\mathrm{H}$ amination of thiophene- $S, S$-dioxide, which is different from the conventional method. 

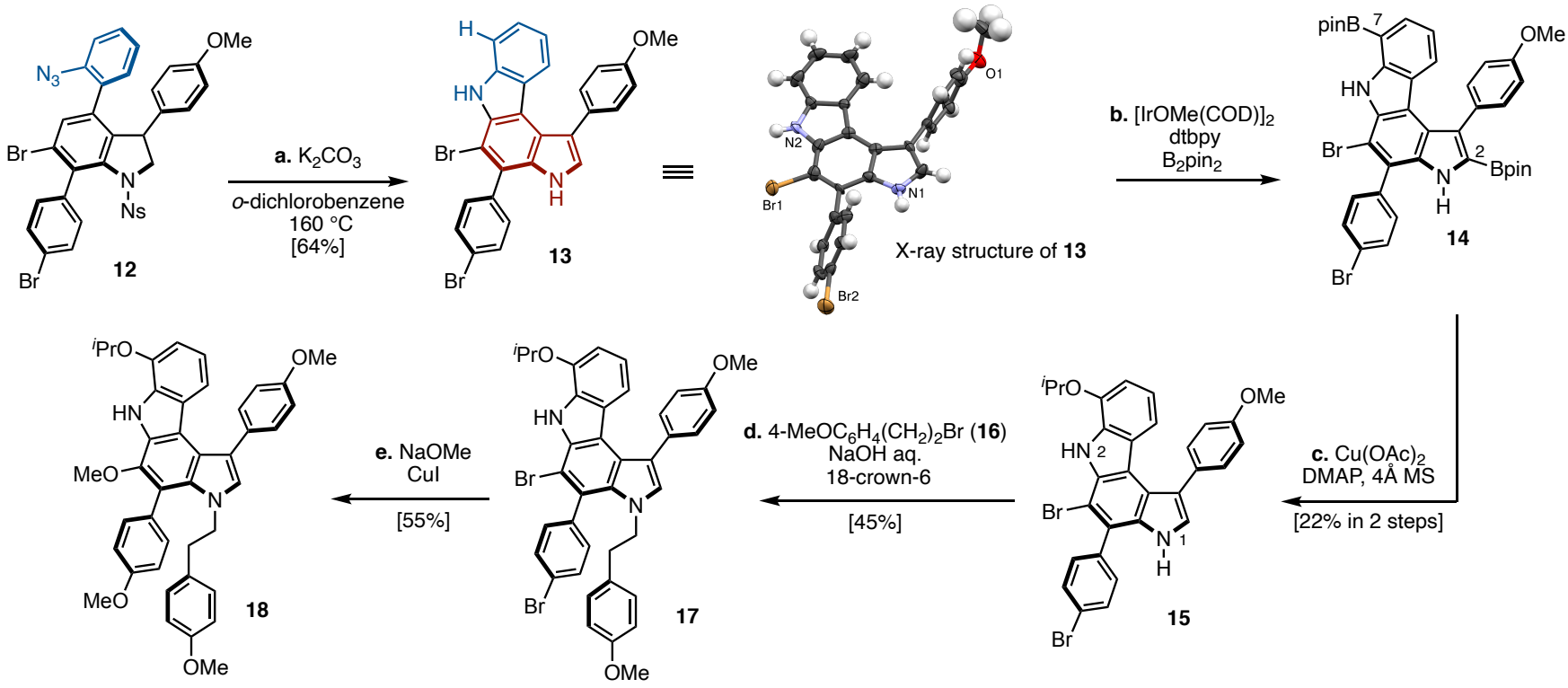

Fürstner's intermediate

${ }^{a}$ Conditions: (a) $\mathrm{K}_{2} \mathrm{CO}_{3}$ (1.0 equiv), $o$-dichlorobenzene, $160^{\circ} \mathrm{C}, 2 \mathrm{~h}$, air $(64 \%)$, ORTEP drawing of 13 with $50 \%$ thermal ellipsoid; (b) $\mathrm{B}_{2}$ pin 2 (2.0 equiv), $30 \mathrm{~mol} \%$ dtbpy, $15 \mathrm{~mol} \%[\mathrm{IrOMe}(\mathrm{COD})]_{2}, \mathrm{THF}, 70^{\circ} \mathrm{C}, 12 \mathrm{~h}$; (c) $\mathrm{Cu}(\mathrm{OAc})_{2}\left(1.0\right.$ equiv), DMAP $\left(2.0\right.$ equiv), ${ }^{2} \mathrm{PrOH}, 4 \AA \mathrm{MS}^{\circ}, \mathrm{CH}_{2} \mathrm{Cl}_{2}, 40{ }^{\circ} \mathrm{C}$, $12 \mathrm{~h}$ ( $22 \%$ in 2 steps); (d) 16 (3.0 equiv), $\mathrm{NaOH}$ aq. (3.0 equiv), 18-crown-6 (6.0 equiv), THF (45\%); (e) CuI (6.0 equiv), $\mathrm{NaOMe} \mathrm{(60} \mathrm{equiv),}$ $\mathrm{DMF} / \mathrm{MeOH}, 100^{\circ} \mathrm{C}, 12 \mathrm{~h}(55 \%)$.

From here, a four-step functionalization including $\mathrm{C}-\mathrm{H}$ borylation led to a known intermediate, and the formal syntheses of dictyodendrins B, C, and E were achieved. Furthermore, pyrrolocarbazole 15 with unsubstituted $\mathrm{C} 2$ and $\mathrm{N} 1$ positions could be a common intermediate toward the synthesis of other dictyodendrin analogues, which are currently ongoing projects in our laboratory.

\section{ASSOCIATED CONTENT}

\section{Supporting Information}

The Supporting Information is available free of charge.

Spectroscopic data for all compounds including ${ }^{1} \mathrm{H},{ }^{13} \mathrm{C}$ NMR spectra, and crystallographic data (PDF). CCDC 2070911 contains the supplementary crystallographic data for this paper.

\section{AUTHOR INFORMATION}

\section{Corresponding Author}

*junyamaguchi@waseda.jp

\section{Author Contributions}

Junichiro Yamaguchi: 0000-0002-3896-5882

\section{Notes}

No competing financial interests have been declared.

\section{ACKNOWLEDGMENT}

This work was supported by JSPS KAKENHI Grant Number JP19H02726 (to J.Y.). This work was partly supported by JST ERATO Grant Number JPMJER1901. We thank Dr. Kenta Kato (Waseda University) for assistance with X-ray crystallography. The Materials Characterization Central Laboratory in Waseda University is acknowledged for the support of HRMS measurements.

\section{REFERENCES}

(1) (a) Warabi, K.; Matsunaga, S.; van Soest, R. W. M.; Fusetani, N. Dictyodendrins A-E, the First Telomerase-Inhibitory Marine Natural Products from the Sponge Dictyodendrilla verongiformis. J. Org. Chem. 2003, 68, 2765-2770. (b) Zhang, H.; Conte, M. M.; Khalil, Z.; Huang, X.-C.; Capon, R. J. New Dictyodendrins as BACE Inhibitors from a Southern Australian Marine Sponge, Ianthella sp.. RSC Adv. 2012, 2, 4209-4214.

(2) Seimiya, H. Drug Deliv. Syst. 2006, 21, 24-31.

(3) Baxter, E. W.; Conway, K. A.; Kennis, L.; Bischoff, F.; Mercken, M. H.; De Winter, H. L.; Reynolds, C. H.; Tounge, B. A.; Luo, C.; Scott, M. K.; Huang, Y.; Braeken, M.; Pieters, S. M. A.; Berthelot, D. J. C.; Masure, S.; Bruinzeel, W. D.; Jordan, A. D.; Parker, M. H.; Boyd, R. E.; Qu, J.; Alexander, R. S.; Brenneman, D. E.; Reitz, A. B. 2-Amino3,4-dihydroquinazolines as Inhibitors of BACE-1 ( $\beta$-Site APP Cleaving Enzyme): Use of Structure Based Design to Convert a Micromolar Hit into a Nanomolar Lead. J. Med. Chem. 2007, 50, 4261-4264.

(4) (a) Fürstner, A.; Domostoj, M. M.; Scheiper, B. Total Synthesis of Dictyodendrin B. J. Am. Chem. Soc. 2005, 127, 11620-11621. (b) Fürstner, A.; Domostoj, M. M.; Scheiper, B. Total Synthesis of the Telomerase Inhibitors Dictyodendrin B, C, and E. J. Am. Chem. Soc. 2006, 128, 8087-8094. (c) Hirao, S.; Sugiyama, Y.; Iwao, M.; Ishibashi, F. Synthetic Approach to Telomerase Inhibitor Dictyodendrin B: Synthesis of the Pyrrolo[2,3-c] carbazole Core. Biosci. Biotechnol. Biochem. 2009, 73, 1764-1772. (d) Hirao, S.; Yoshinaga, Y.; Iwao, M.; Ishibashi, F. A Formal Total Synthesis of the Telomerase Inhibitor Dictyodendrin B. Tetrahedron Lett. 2010, 51, 533-536. (e) Okano, K.; Fujiwara, H.; Noji, T.; Fukuyama, T.; Tokuyama, H. Total Synthesis of Dictyodendrin A and B. Angew. Chem., Int. Ed. 2010, 49, 5925-5929. (f) Okano, K.; Fujiwara, H.; Noji, T.; Fukuyama, T.; Tokuyama, H. Total Synthesis of Dictyodendrins A-E. Chem. Asian J. 2011, 6, 560-572. (g) Liang, J.; Hu, W.; Tao, P.; Jia, Y. Total Synthesis of Dictyodendrins B and E. J. Org. 
Chem. 2013, 78, 5810-5815. (h) Tao, P.; Liang, J.; Jia, Y. Total Synthesis of Dictyodendrins B and E, and Formal Synthesis of Dictyodendrin C. Eur.J. Org. Chem. 2014, 5735-5748. (i) Yamaguchi, A. D.; Chepiga, K. M.; Yamaguchi, J.; Itami, K.; Davies, H. M. L. Concise Syntheses of Dictyodendrins A and F by a Sequential C-H Functionalization Strategy. J. Am. Chem. Soc. 2015, 137, 644-647. (j) Pitts, A. K.; O’Hara, F.; Snell, R. H.; Gaunt, M. J. A Concise and Scalable Strategy for the Total Synthesis of Dictyodendrin B Based on Sequential C-H Functionalization. Angew. Chem., Int. Ed. 2015, 54, 5451-5455. (k) Zhang, W.; Ready, J. M. A Concise Total Synthesis of Dictyodendrins F, H, and I Using Aryl Ynol Ethers as Key Building Blocks. J. Am. Chem. Soc. 2016, 138, 10684-10692. (1) Matsuoka, J.; Matsuda, Y.; Kawada, Y.; Oishi, S.; Ohno, H. Total Synthesis of Dictyodendrins by the Gold-Catalyzed Cascade Cyclization of Conjugated Diynes with Pyrroles. Angew. Chem., Int. Ed. 2017, 56, 7444-7448. (m) Matsuoka, J.; Inuki, S.; Matsuda, Y.; Miyamoto, Y.; Otani, M.; Oka, M.; Oishi, S.; Ohno, H. Total Synthesis of Dictyodendrins A-F by the Gold-Catalyzed Cascade Cyclization of Conjugated Diyne with Pyrrole. Chem. Eur.J.2020, 26, 11150-11157. (n) Banne, S.; Reddy, D. P.; Li, W.; Wang, C.; Guo, J.; He, Y. A Unified Modular Synthetic Strategy for Dictyodendrins F, H, I, and G. Org. Lett. 2017, 19, 4996-4999.

(5) Suzuki, S.; Asako, T.; Itami, K.; Yamaguchi, J Modular Synthesis of Heptaarylindole. Org. Biomol. Chem. 2018, 16, 3771-3776.

(6) (a) Suzuki, S.; Segawa, Y.; Itami, K.; Yamaguchi, J. Synthesis and Characterization of Hexaarylbenzenes with Five or Six Different
Substituents Enabled by Programmed Synthesis. Nat. Chem. 2015, 7,227-233. (b) Suzuki, S.; Itami, K.; Yamaguchi, J. Synthesis of Octaaryl Naphthalenes and Anthracenes with Different Substituents Angew. Chem., Int. Ed. 2017, 56, 15010-15013. (c) Asako, T.; Suzuki, S.; Itami, K.; Muto, K.; Yamaguchi, J. Synthesis of A Heptaarylisoquinoline: Unusual Disconnection for Constructing Isoquinoline Frameworks. Chem. Lett. 2018, 47, 968-970. (d) Tanaka, S.; Asako, T.; Ota, E.; Yamaguchi, J. Synthesis of a Pentaarylcarbazole: Installation of Different Aryl Groups on a Benzenoid Moiety. Chem. Lett. 2020, 49, 918-920. (e) Asako, T.; Suzuki, S.; Tanaka, S.; Ota, E.; Yamaguchi, J. Synthesis of Decaarylanthracene with Nine Different Substituents. J. Org. Chem. 2020, 85, 15437-15448.

(7) Taylor, S. K.; Clark, D. L.; Heinz, K. J.; Schramm, S. B.; Westermann, C. D.; Barnell, K. K. Friedel-Crafts Reactions of Some Conjugated Epoxides. J. Org. Chem. 1983, 48, 592-596.

(8) Vaillant, F. L.; Courant, T.; Waser, J. Room-Temperature Decarboxylative Alkynylation of Carboxylic Acids Using Photoredox Catalysis and EBX Reagents. Angew. Chem., Int. Ed. 2015, 54, 1120011204.

(9) Liyu, J.; Sperry, J. Synthesis of Putative Clausenal from Carbazole Using Sequential C-H Borylations. Tetrahedron Lett. 2017, 58, 1699-1701.

(10) Loach, R. P.; Fenton, O. S.; Amaike, K.; Siegel, D. S.; Ozkal, E.; Movassaghi, M. C7-Derivatization of C3-Alkylindoles Including Tryptophans and Tryptamines. J. Org. Chem. 2014, 79, 11254-11263. 